\title{
Toward a ground-motion logic tree for probabilistic seismic hazard assessment in Europe
}

\section{Journal Article}

\section{Author(s):}

Delavaud, Elise; Cotton, Fabrice; Akkar, Sinan; Scherbaum, Frank; Danciu, Laurentiu (D); Beauval, Céline; Drouet, Stéphane; Douglas, John; Basili, Roberto; Sandikkaya, M. Abdullah; Segou, Margaret; Faccioli, Ezio; Theodoulidis, Nikos

Publication date:

2012-07

Permanent link:

https://doi.org/10.3929/ethz-b-000049791

Rights / license:

In Copyright - Non-Commercial Use Permitted

Originally published in:

Journal of Seismology 16(3), https://doi.org/10.1007/s10950-012-9281-z 


\title{
Toward a ground-motion logic tree for probabilistic seismic hazard assessment in Europe
}

\author{
Elise Delavaud - Fabrice Cotton - Sinan Akkar • Frank Scherbaum • \\ Laurentiu Danciu • Céline Beauval · Stéphane Drouet • John Douglas · \\ Roberto Basili • M. Abdullah Sandikkaya • Margaret Segou • \\ Ezio Faccioli • Nikos Theodoulidis
}

Received: 4 August 2011 / Accepted: 24 January 2012 / Published online: 22 February 2012

(C) Springer Science+Business Media B.V. 2012

\begin{abstract}
The Seismic Hazard Harmonization in Europe (SHARE) project, which began in June 2009, aims at establishing new standards for probabilistic seismic hazard assessment in the EuroMediterranean region. In this context, a logic tree for ground-motion prediction in Europe has been constructed. Ground-motion prediction equations (GMPEs) and weights have been determined so that the logic tree captures epistemic uncertainty in ground-motion prediction for six different tectonic regimes in Europe. Here we present the strategy that we adopted to build such a logic tree. This strategy has the particularity of combining two complementary and independent approaches: expert judgment and data testing. A set
\end{abstract}

\footnotetext{
E. Delavaud $(\bowtie) \cdot$ F. Cotton · C. Beauval · S. Drouet ISTerre, Université Joseph Fourier, CNRS, BP 53, 38041 Grenoble, France

e-mail: elise.delavaud@sed.ethz.ch

E. Delavaud · L. Danciu

Swiss Seismological Service, Institute of Geophysics, ETH Zurich, Sonneggstrasse 5, NO, 8092 Zurich, Switzerland
}

S. Akkar · M. A. Sandikkaya - M. Segou

Earthquake Engineering Research Center, Department of Civil Engineering, METU, 06531 Ankara, Turkey

F. Scherbaum

Institute of Earth and Environmental Sciences, University of Potsdam, Karl-Liebknecht-Strasse 24-25, 14476 Golm, Germany of six experts was asked to weight pre-selected GMPEs while the ability of these GMPEs to predict available data was evaluated with the method of Scherbaum et al. (Bull Seismol Soc Am 99:3234-3247, 2009). Results of both approaches were taken into account to commonly select the smallest set of GMPEs to capture the uncertainty in ground-motion prediction in Europe. For stable continental regions, two models, both from eastern North America, have been selected for shields, and three GMPEs from active shallow crustal regions have been added for continental crust. For subduction zones, four models, all nonEuropean, have been chosen. Finally, for active shallow crustal regions, we selected four models,

\author{
J. Douglas \\ RIS/RSI, BRGM, 3 avenue C. Guillemin, BP 36009 , \\ 45060 Orléans Cedex 2, France \\ R. Basili \\ Istituto Nazionale di Geofisica e Vulcanologia, \\ Via di Vigna Murata 605, 00143 Rome, \\ Italy \\ E. Faccioli \\ Politecnico di Milano, Piazza L. da Vinci, 32, 20133 \\ Milan, Italy \\ N. Theodoulidis \\ ITSAK, P.O. Box 53, Finikas 55102 Thessaloniki, \\ Greece
}


each of them from a different host region but only two of them were kept for long periods. In most cases, a common agreement has been also reached for the weights. In case of divergence, a sensitivity analysis of the weights on the seismic hazard has been conducted, showing that once the GMPEs have been selected, the associated set of weights has a smaller influence on the hazard.

Keywords Logic trees - Ground-motion prediction equations - Expert judgment . Model selection $\cdot$ Seismic hazard assessment

\section{Introduction}

Following the SESAME (Seismotectonics and Seismic Hazard Assessment of the Mediterranean Basin, 1996-2000) project, the Seismic Hazard Harmonization in Europe (SHARE) project (http:// www.share-eu.org) is one of the large interna- tional research initiatives that have been recently launched to harmonize hazard estimates across political boundaries and to derive procedurally consistent pan-national hazard models. As a regional program of the Global Earthquake Model (GEM) project (http://www.globalquakemodel. org), the SHARE project aims at defining methods for seismic hazard and loss assessment in the Euro-Mediterranean region which will become standards at global and regional scales.

The team responsible for ground-motion prediction in the SHARE project (WP4 group, see Table 1) has been working on the definition of a reference European model that captures the complete center, body and range of possible ground motions in Europe and tackles the unresolved question of regional variations in ground motions. The construction of logic trees that express this variability and the associated epistemic uncertainty is a multi-step procedure that required a common effort in characterizing ground shaking in Europe and identifying reliable equations for

Table 1 SHARE WP4 group involved in the building of the logic tree for ground-motion prediction

\begin{tabular}{|c|c|c|}
\hline Coordinators and & Elise Delavaud & ISTerre, Grenoble, France/ETH, Zürich, Switzerland \\
\hline \multirow[t]{3}{*}{ Methodology definition } & Fabrice Cotton & ISTerre, Grenoble, France \\
\hline & Sinan Akkar & METU, Ankara, Turkey \\
\hline & Frank Scherbaum & $\begin{array}{l}\text { Institute of Earth and Environmental Science, } \\
\text { Potsdam, Germany }\end{array}$ \\
\hline \multirow[t]{6}{*}{ Experts } & Julian Bommer & Imperial College, London, UK \\
\hline & Fabian Bonilla & IFSSTAR, Paris, France \\
\hline & Hilmar Bungum & NORSAR/ICG, Kjeller, Norway \\
\hline & John Douglas & BRGM, Orléans, France \\
\hline & Ezio Faccioli & Politecnico di Milano, Milan, Italy \\
\hline & Nikos Theodoulidis & ITSAK, Thessaloniki, Greece \\
\hline \multirow[t]{14}{*}{ Participants } & Laurentiu Danciu (sensitivity analysis) & ETH, Zürich, Switzerland \\
\hline & Céline Beauval (data testing) & ISTerre, Grenoble, France \\
\hline & Stéphane Drouet (models pre-selection) & ISTerre, Grenoble, France \\
\hline & John Douglas (models pre-selection) & BRGM, Orléans, France \\
\hline & Roberto Basili (zonation map) & INGV, Rome, Italy \\
\hline & Abdullah Sandikkaya (data testing) & METU, Ankara, Turkey \\
\hline & Margaret Segou (data testing) & METU, Ankara, Turkey \\
\hline & Ezio Faccioli (volcanic zones) & Politecnico di Milano, Milan, Italy \\
\hline & Nikos Theodoulidis (data testing) & ITSAK, Thessaloniki, Greece \\
\hline & Donat Fäh & ETH, Zürich, Switzerland \\
\hline & Benjamin Edwards & ETH, Zürich, Switzerland \\
\hline & Pierre-Yves Bard & ISTerre, Grenoble, France \\
\hline & Kyriazis Pitilakis & University of Thessaloniki, Thessaloniki, Greece \\
\hline & Marco Pagani & GEM Foundation, Pavia, Italy \\
\hline
\end{tabular}


the prediction of ground-motion parameters of interest together with measures of uncertainties.

Within the large geographical area covered by SHARE, there is a wide variation in terms of the magnitude and distance ranges that influence probabilistic seismic hazard assessment (PSHA). PSHA in Europe is not only controlled by large magnitudes. As a matter of fact, probabilistic disaggregation analyses indicate that in many seismically active regions of Europe, the seismic hazard for $10 \%$ exceedance in 50 years level and short vibration periods (fundamental for ultimate limit state verifications of most structures) tends to be controlled by nearby earthquakes (distance $<20 \mathrm{~km}$ ) in the 4.5 to 5.5 magnitude range. Beauval et al. (2008) showed that in active regions of France, magnitudes 4 to 5 are also responsible for a non-negligible contribution to the hazard even for return periods as large as 10,000 years. The above observation is commonly found, for example, for Italian sites in active areas and, obviously, is particularly true for low seismicity regions, i.e., north of the Alps (Faccioli and Villani 2009). This is why ground-motion prediction equations (GMPEs) that include events with magnitudes down to $M_{\mathrm{w}} 4$ in their datasets should also be considered. Concerning the influence of the larger magnitudes on hazard, evaluations tend to depend to some extent on the model of earthquake sources adopted, e.g., whether extended zones, or fault sources (FS), or smoothed seismicity. In active regions of southern Italy (notably the Calabrian Arc), where maximum historical magnitudes exceed 7 and which are certainly among the most active in the Mediterranean area, recent seismic hazard studies for sites lying within source zones indicate that magnitudes $>6.5$ in the distance range within $20 \mathrm{~km}$ dominate hazard only at return periods of 5,000 years and vibration periods of $1 \mathrm{~s}$ and larger (Faccioli and Villani 2009). In such regions, even at return periods as large as 1,500 years and at vibration periods of $1 \mathrm{~s}$, hazard is typically controlled by magnitudes $\leq 6.0$ in the short distance range. On the other hand, again considering southern Italy, sites lying at few tens of kilometers from the boundaries of model source zones are mostly affected by $M>6.5$ starting from return periods of 1,000 years or so, in the whole range of vibration periods. If smoothed seismicity representations are used instead, things change to some extent, in that - for a given return period-lower magnitudes tend to dominate.

In this paper, we describe the methodology that we adopted to build the logic tree for PSHA in Europe. This process is illustrated in Fig. 1. The goal of this strategy is to identify the smallest set of GMPEs to capture the epistemic uncertainty in ground-motion prediction in Europe. The particularity of our approach is that we do not only take into account the judgment of experts to select and rank models but we also use data to guide our choice and weights. Thanks to an increasing amount of strong-motion data, data-driven guidance is indeed now feasible and can give valuable information about the ability of GMPEs to predict ground motion in different regions (e.g., Drouet et al. 2007; Allen and Wald 2009; Delavaud et al. 2012).

The structure of this paper follows the adopted procedure. First, we show how a list of GMPEs for each tectonic regime was selected from the many existing models using exclusion criteria. In a second step, we describe the expert judgment, including the conditions imposed to the experts

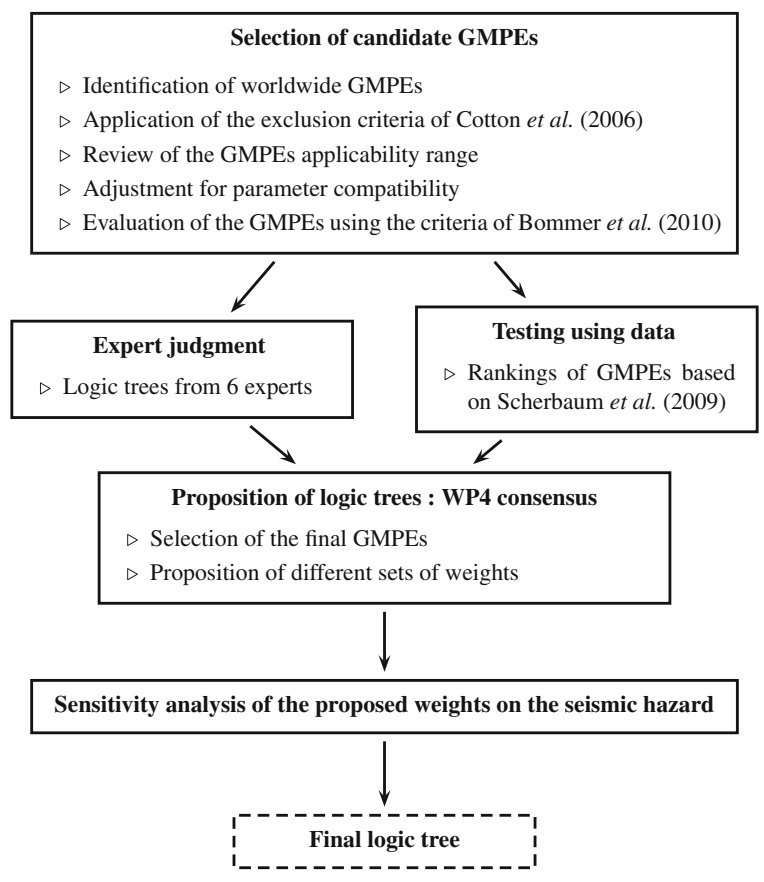

Fig. 1 Process adopted for the construction of the groundmotion logic tree for Europe 
and the weights that they chose. We pay particular attention to the rationale behind the choices of the experts and expose what we learnt from them. The third step consists in the testing of the candidate GMPEs using data. GMPEs are ranked according to a criteria, the negative average sample loglikelihood, proposed by Scherbaum et al. (2009) and based on information theory. In particular, we estimated to what degree the data support or reject a model with respect to the state of non-informativeness defined by uniform weighting. The following section describes how GMPEs were selected taking expert judgment and data testing into account and different sets of weights proposed as a consensus within the SHARE WP4 group. Finally, we present the results of a sensitivity analysis of the weights on hazard maps to help us make a final choice. The goal of this paper is to make the SHARE GMPE logic tree methodology transparent and reproducible.

\section{Pre-selection of ground-motion prediction equations}

The pre-selection of GMPEs is first guided by the seismotectonic description of the area covered by the SHARE project (Fig. 2). The SHARE source model also influences ground-motion prediction, especially in terms of distance calculation. This source model combines modern source types (area, fault, and point sources) within a logic tree to account for the inherent uncertainty in the expert views on seismicity. The source logic tree considers the different source types within the principal methodologies used: the zone-

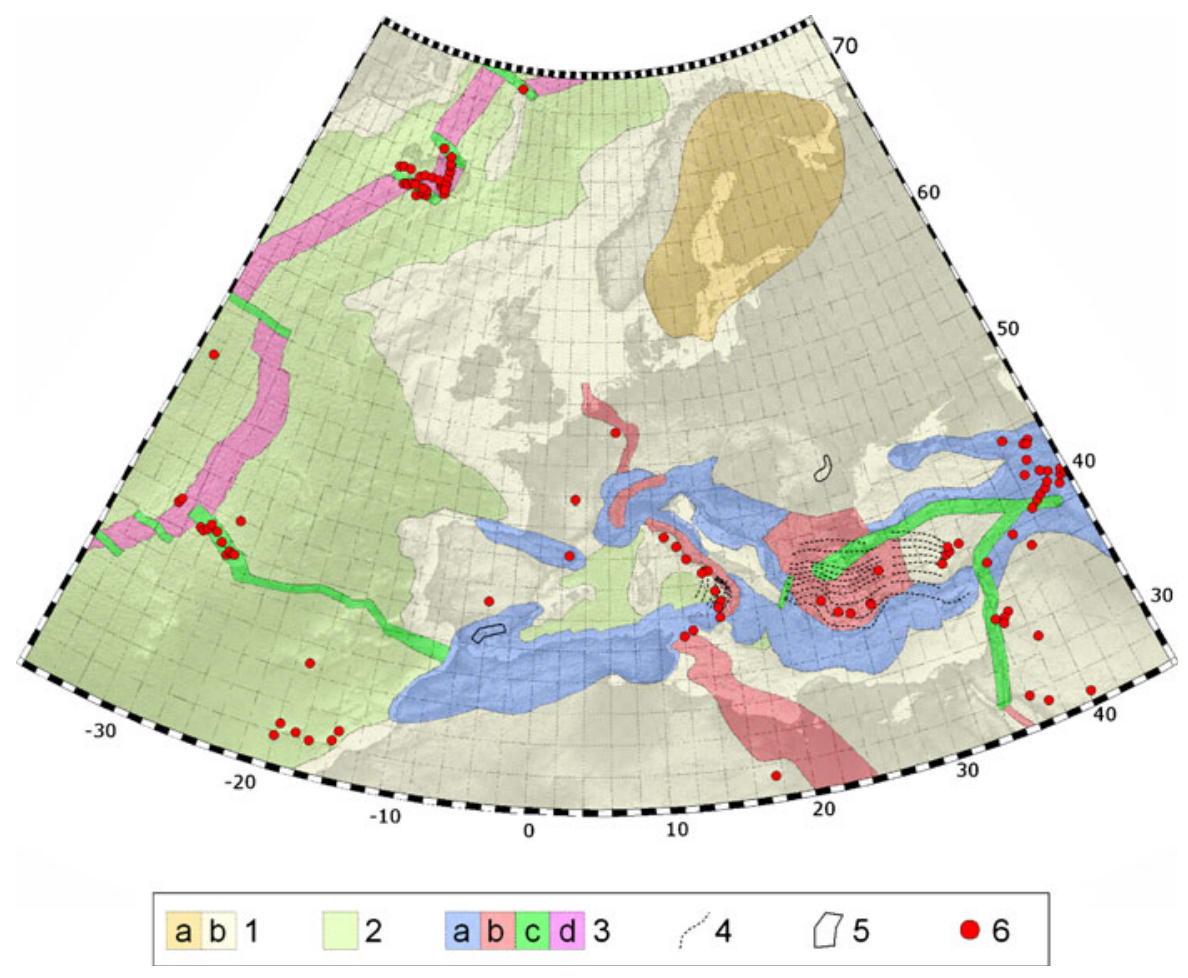

Fig. 2 Seismotectonic map of the Euro-Mediterranean area developed for the SHARE project by WP3.2. 1 SCR, shield $(a)$ and continental crust $(b) ; 2$ oceanic crust; 3 ASCR, compression-dominated areas $(a)$ including thrust or reverse faulting, associated transcurrent faulting (e.g., tear faults), and contractional structures in the upper plate of subduction zones (e.g., accretionary wedges), extension-dominated areas $(b)$ including associated transcurrent faulting, major strike-slip faults and transforms $(c)$, and mid oceanic ridges $(d) ; 4$ subduction zones shown by contours at $50-\mathrm{km}$-depth interval of the dipping slab; 5 areas of deep-focus non-subduction earthquakes; 6 active volcanoes and other thermal/magmatic features 
based (Cornell 1968) and the kernel-smoothed approach (Grünthal et al. 2010; Hiemer et al. 2011). Final details on the source models can be found within the reports of the SHARE project at http://www.share-eu.org or within a yet to be written manuscript on the new Euro-Mediterranean hazard model.

The pre-selection of GMPEs was realized from an already compiled list by Douglas (2008) that contains over 250 published ground-motion models, to retain a subset of the most robust equations for all the existing seismotectonic regimes in the wider European region. Six broad tectonic domains were identified for ground-motion prediction to represent the region covered by the SHARE project (Fig. 2): Stable continental regions (SCR) include the shield (Baltic) where Precambrian crystalline igneous or metamorphic rocks crop out and are characterized by low wave attenuation and a low deformation rate, and continental crust (most of Europe and Africa) with low deformation rate; oceanic crust includes mainly the eastern Atlantic and small patches in the Mediterranean Sea; active shallow crustal regions (ASCR) mainly outline the plate boundaries but occur also in the continental interiors at places with significant rate of deformation; subduction zones (SZ) such as the Calabrian, Hellenic, and Cyprus arcs; areas of deep focus non-subduction earthquakes, such as Vrancea (Romania) or the Betics (Spain); and active volcanoes. For this preselection, it was decided to apply the seven exclusion criteria proposed by Cotton et al. (2006), briefly: (1) the model is from a clearly irrelevant tectonic regime, (2) the model is not published in an international peer-reviewed journal, (3) the documentation of model and its underlying dataset is insufficient, (4) the model has been superseded by more recent publications, (5) the frequency range of the model is not appropriate for engineering application, (6) the model has an inappropriate functional form, and (7) the regression method or regression coefficients are judged to be inappropriate. From the existing GMPEs, six models remained for SCR, eight for SZ, 19 for ASCR including six regional or local models, one model for volcanic zones (McVerry et al. 2006), and one for areas of deep focus non-subduction earthquakes (Sokolov et al. 2008). No model for the prediction of ground motions from oceanic crustal earthquakes was available in the international literature, but models for ASCR and SCR have been suggested to account for such seismotectonic regimes. The engineering needs, evaluated at the beginning of the project, were taken into account by favoring models well calibrated in the period range between 0.02 and $10 \mathrm{~s}$. Most of existing models are, however, not applicable for periods greater than $3 \mathrm{~s}$, and hence, a specific logic tree was built to ensure PSHA computations for periods between 3 and $10 \mathrm{~s}$.

As a second step, these pre-selected GMPEs have been analyzed and compared in order to identify their weaknesses and limitations in the light of the criteria set proposed by Bommer et al. (2010). Considering the rapid increase in published GMPEs for ASCR (in particular), Bommer et al. (2010) updated the exclusion criteria of Cotton et al. (2006) to reflect the stateof-the-art in ground-motion prediction. The new exclusion criteria especially aim at identifying the robust and well-constrained models based on new quality standards in the formulation and derivation of models as well as considering their applicability range in terms of spectral ordinates, magnitude, and distance. In particular, magnitude and distance ranges should be large enough so that the need for extrapolations when conducting PSHA is minimized. In addition, the number of earthquakes per magnitude and the number of records per different distance intervals should be maximized. A detailed comparative study between the models of each tectonic regime has been conducted. In particular, they compared the predicted ground-motion amplitudes by the GMPEs for different scenarios (in terms of magnitude, distance, and period) and extracted the main characteristics of the models that are summarized in Table 2 for SCR, in Table 3 for SZ, and in Table 4 for ASCR. In these tables, we report the type and range for the magnitude and the distance, the spectral period band, as well as the inclusion of PGA and/or peak ground velocity (PGV) estimations by the candidate GMPEs. We also indicate whether the site classification is based on a continuous function of $v_{\mathrm{S} 30}$ or on generic site classes in terms of $v_{\mathrm{S} 30}$ intervals. The tables also list the horizontal component definitions of the 

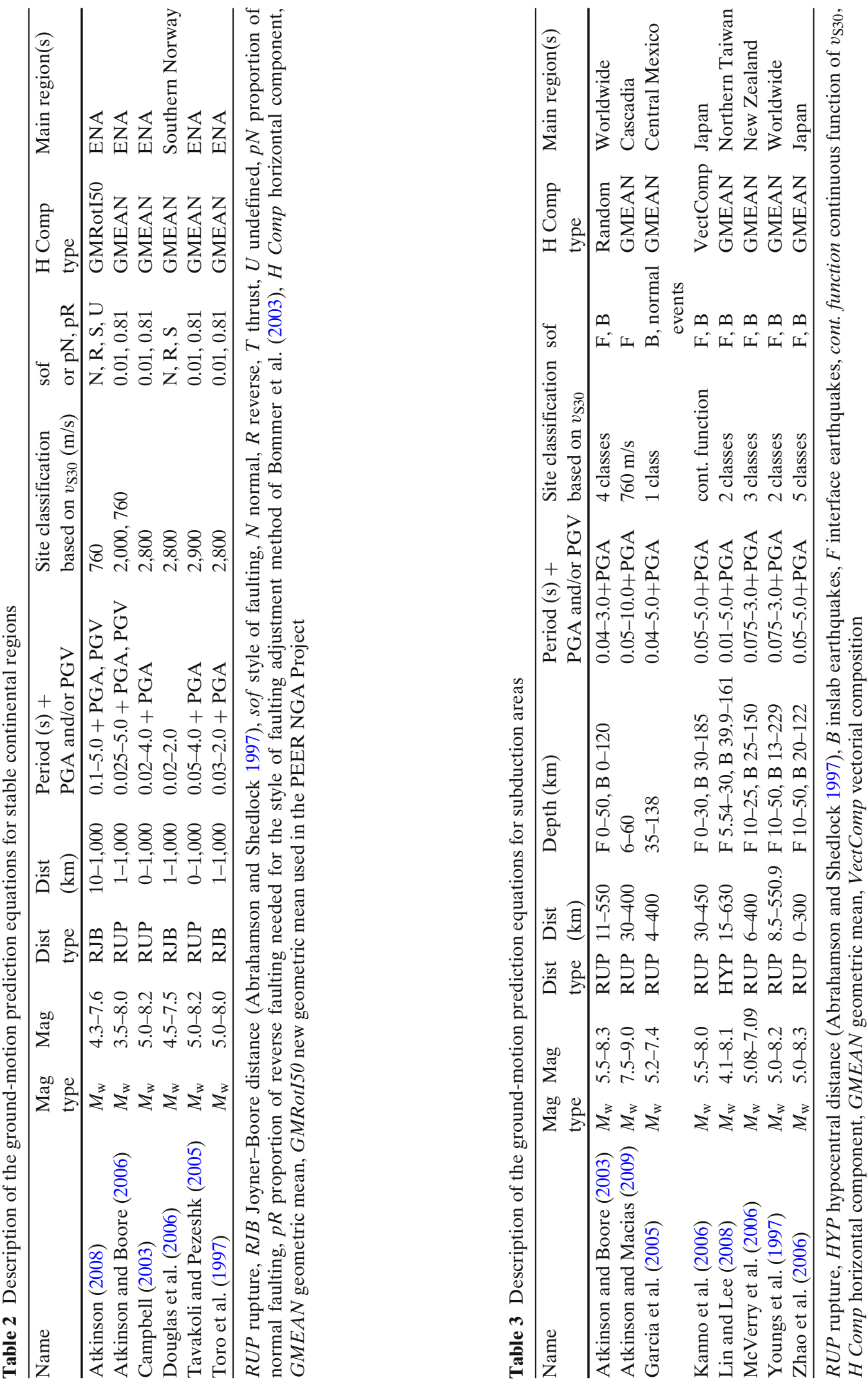


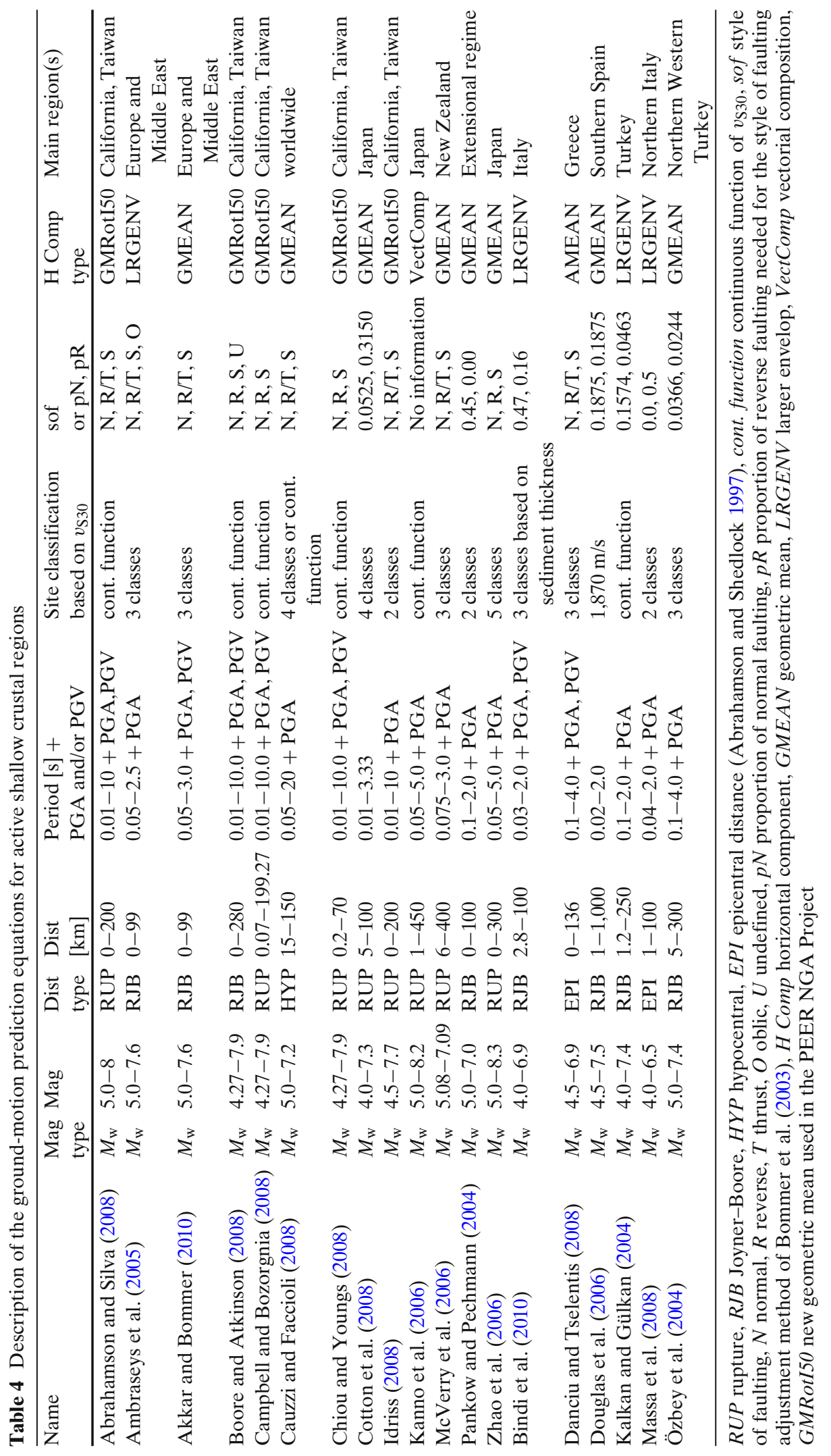


GMPEs that vary among the models. Moreover, some of the models do not use style of faulting as a predictor variable. In order to combine the GMPEs within a logic tree framework, component and style-of-faulting adjustments have been performed. Horizontal components are converted using the conversion coefficients determined by Beyer and Bommer (2006). For models which do not consider the style of faulting, adjustment factors depending on the proportions of normal and reverse events in the underlying database of each model are applied using the approach proposed in Bommer et al. (2003). These factors are given in the tables except for SZ models, which do not explicitly consider the style of faulting but differentiate inslab earthquakes from interface earthquakes, taking into account both the mechanism and the depth of the earthquake. The effects of the adjustment strategies are presented in Drouet et al. (2010). Finally, we did not take non-linear effects into account as the seismic hazard is computed for rock sites. Our model selection is thus focusing on the rock part of GMPEs.

As a result of the model analysis, the members of the WP4 team discussed their concerns about the predictive ability and the weaknesses of the models. Reservations were expressed for the next-generation attenuation (NGA) models of Abrahamson and Silva (2008), Campbell and Bozorgnia (2008), and Chiou and Youngs (2008) because they require too many estimator parameters that are not available in all European earthquake-prone regions. This limitation can be partially overcome by using the a priori estimations of these unknown input parameters given by the methodology proposed in Kaklamanos et al. (2011). Models that suffer from restrictions in the definition of predictive variables were also questioned: The SZ model of Garcia et al. (2005) only considers inslab earthquakes, Atkinson and Macias (2009) only consider large interface earthquakes, the NGA model of Idriss (2008) does not cover sites with $v_{\mathrm{S} 30}$ values less that $450 \mathrm{~m} / \mathrm{s}$, and finally, Kanno et al. (2006) do not provide proportions of normal and reverse faulting events thereby preventing style-of-faulting adjustments. The model of Cotton et al. (2008) was also ques- tioned because it does not include style of faulting as a predictor variable and they might have included subduction interface events in their ASCR dataset since the selection of earthquakes was based on focal depth only. Finally, reservations were expressed for the models of Tavakoli and Pezeshk (2005) and of Ambraseys et al. (2005) as they are similar to Campbell (2003) and Akkar and Bommer (2010), respectively, and for the model of Özbey et al. (2004) which was derived from data from the 1999 earthquakes in Turkey that were recorded within a limited area. Although these GMPEs suffer from the above restrictions, they were considered by the experts and in the testing.

There are obviously large differences in terms of number of GMPEs between the three tectonic regimes and also in terms of their host regions. For stable continental regions, all the GMPEs except Douglas et al. (2006) were derived from eastern North America (ENA) data whereas ASCR regime includes GMPEs from all over the world (although mainly California, Europe, and Japan). The selection for subduction zones includes no European candidate ground-motion model.

Finally, we acknowledge that the pre-selected GMPEs may not be calibrated homogeneously in all the parameter space relevant for PSHA in Europe, especially for low magnitudes $\left(M_{\mathrm{w}}<5\right)$. The development of new GMPEs was beyond the scope of the present project, and for this reason and the lack of homogeneous local datasets, we have not applied the calibration of existing models using local data, e.g., following the method by Scasserra et al. (2009). We recognize that there is a need to start to apply these new methods, at least in Turkey and Italy, where local data are available.

The pre-selected GMPEs have been subsequently evaluated in two parallel steps. In one approach, a group of experts were asked to propose the logic tree weights for these GMPEs. In the other approach, ground-motion records, whenever available, were used to test the ability of the GMPEs to model the overall trends of the ground motions in each tectonic region. We present now these two complementary approaches. 


\section{Expert judgment}

Since the 1970s, there has been an increasing interest in the use of expert judgment to help in decision making by formalizing and quantifying expert judgment on problems that involve uncertainties (e.g., Cooke 1991; Goossens et al. 2000). Private agencies as well as academia have recourse to this approach especially when data are unavailable or inadequate, and this is why it has been, until recently, the only method used to select and weigh GMPEs for probabilistic seismic hazard assessment. Although guidance for expert judgment is given by the Senior Seismic Hazard Analysis Committee in Budnitz et al. (1997), there is no clear standard procedure for the selection and weighting of GMPEs by experts. In this section, we present the strategy that we adopted for the determination of logic tree weights from a group of experts.

We composed a group of six experts working in five different countries in academia or public institutions in Europe (see Table 1). Six seemed to be a good number, to have enough different points of view without too much redundancy. They were chosen for their great experience with GMPEs (e.g., some of them developed GMPEs) and also for their experience of PSHA in specific countries such as Italy, France, or Greece. Four people (the first four authors of the present paper) defined the guidelines and the processing of the expert judgment. We asked the experts to propose logic tree weights expressing their degree of belief in the ability of candidate GMPEs to predict earthquake ground motions in different tectonic regimes in Europe. We did not guide the experts in how to assign their weights (e.g., whether all GMPEs should be weighted or not), since no clear methodology was available at that time. However, we asked them to explain the rationale behind their weighting strategy. Weights had to be assigned for each tectonic regime (with a differentiation between shield and continental crust for SCR and between interface and inslab earthquakes for SZ) for different ranges in spectral frequency $(f)$, magnitude $\left(M_{\mathrm{w}}\right)$, and distance $(d): f \leq 1 / 3 \mathrm{~Hz}$, $1 / 3 \mathrm{~Hz}<f \leq 25 \mathrm{~Hz}$, or $f>25 \mathrm{~Hz} ; M_{\mathrm{w}} \leq 5$ or $M_{\mathrm{w}}>5$; and $d \leq 10 \mathrm{~km}, 10 \mathrm{~km}<d \leq 100 \mathrm{~km}$,
$100 \mathrm{~km}<d \leq 200 \mathrm{~km}$, or $d>200 \mathrm{~km}$. By doing so, we wanted to see whether or not the experts would consider the frequency-magnitudedistance dependency for the logic tree weights. Finally, the experts did not communicate with each other to have independent alternatives for logic tree weights. They also did not know about the testing results conducted by using the empirical data (see next section). However, they were provided with the characteristics of the GMPEs that are presented.

A lesson that we learned from the experts is that assigning weights to GMPEs is not straightforward, especially for such a large number of models and with distinctions in terms of frequency, magnitude, and distance. We also realized that the time limit imposed for the entire decision process was quite limited for this task (5 weeks). In particular, some experts raised the possibility of assigning zero weights to some of the GMPEs, indirectly raising the question of what logic tree weights represent. This led to a lively discussion between the WP4 members and the experts during a meeting where experts presented their weighting strategy. Experts had a common approach: They selected a set of models which enabled them to capture epistemic uncertainty as much as possible. For some of the experts, a small number of GMPEs (two to four) was sufficient (not all models are used although they could be appropriate). On the other hand, some experts selected many or all the candidate GMPEs assigning small weights $(<0.1)$ for the less favorable ones. Although logic trees are now widely used, we realized that it is not clear yet how weights should be assigned and what they should be assumed to represent. Scherbaum and Kühn (2011) recently showed the importance of treating logic tree weights as probabilities instead of simply as generic quality measures of GMPEs, which are subsequently normalized. In particular, they show the danger of using a performance/grading matrix approach (independently assigning of grades to different quality criteria) where the normalization process can lead to an apparent insensitivity to the weights. In order to achieve consistency with a probabilistic framework, Scherbaum and Kühn (2011) proposed to assign weights in a sequential 
fashion (e.g., if the first GMPE of three selected gets a 0.6 weight, then the sum of the weights for the two remaining models is 0.4 ).

The first conclusion of the experts was that the number of selected GMPEs should be kept as small as possible (between two and five) to prevent the logic tree for ground-motion prediction being too complex, which is especially important for such a wide area considered by the SHARE project. In addition, most of the experts gave weights that are independent of the magnitude, distance, and frequency, except for long periods $(3 \mathrm{~s}<T \leq 10 \mathrm{~s})$ for ASCR. The main motivation behind this choice was to prevent having a discontinuity due to the transition from one logic tree to another one in the uniform hazard spectra produced by PSHA. The experts selected GMPEs which are sufficiently robust to cover a wide range of magnitudes, distances, and spectral periods. Such GMPEs are indeed better able to capture the magnitude scaling of ground motion that decreases when magnitude increases (Cotton et al. 2008; Atkinson and Morrison 2009). Moreover, Bommer et al. (2007) strongly recommended not to apply GMPEs outside and even close to their magnitude limits. Finally, GMPEs developed from limited datasets are more likely to incorporate random earthquake effects (biases) into their models. Therefore, global predictive models were preferred as compared to regional ones. Finally, experts assigned equal weights for the models that they are not familiar with or for which they lack sufficient information.

For stable continental regions, selecting the models was a particular challenge as all but one are derived for ENA and inadequate information about their applicability for Europe is known. Experts made no distinctions between shield and continental crust. Of the six GMPEs proposed for SCR, the expert selection ranged between retaining three or all six. The SCR models by Campbell (2003) and Toro et al. (1997) were selected by all experts. The choice of GMPEs for subduction zones was also a challenging task since none of the pre-selected GMPEs were derived using empirical data from Europe. Due to this particular reason, the experts preferred choosing the global SZ models that cover a wide range of magnitude and distance intervals. Only one expert considered interface and inslab models separately in ranking whereas three experts considered the spectral period ranges while assigning weights. The experts selected two to five GMPEs among the eight models proposed for SZ. Only one model was selected by all the experts, the model of Atkinson and Boore (2003). Contrary to the SCR and SZ regions, the excessive number of GMPEs for the shallow crustal active regions challenged the expert judgment. Regional ASCR models (e.g., Massa et al. 2008; Kalkan and Gülkan 2004; Danciu and Tselentis 2008) were either excluded or given small weights (less than 0.1). The expert choices lean toward global and pan-European models in the ranking of ASCR GMPEs. Of the entire expert group, only two of them considered magnitude-distance-frequency ranges while assigning weights. The experts selected between three to ten GMPEs among the 18 candidate models. The GMPEs by Akkar and Bommer (2010) and of Boore and Atkinson (2008) were the commonly selected models by all experts. Tables 8,9 , and10 summarize the choice of each expert for the three tectonic regimes under the Category based on expert judgment.

\section{Data testing}

To complement the expert opinions described above, testing of the candidate GMPEs against empirical data was undertaken. The goal of this phase was to judge the applicability of candidate models by evaluating their probability to have generated the available data. We used the datadriven method developed by Scherbaum et al. (2009) that implemented an information theoretic approach for the selection and the ranking of GMPEs. The method derived a ranking criterion from the Kullback-Leibler (KL) divergence, which denotes the information loss when a model $g$ defined as a distribution is used to approximate a reference model $f$ (Burnham and Anderson 2002). The KL divergence between two models represented by their probability density functions $f$ and $g$ is defined as:

$D(f, g)=E_{f}\left[\log _{2}(f)\right]-E_{f}\left[\log _{2}(g)\right]$ 
where $E_{f}$ is the statistical expectation taken with respect to $f$.

In the case of GMPE selection, $f$ represents the data-generating process (nature) and is only known through observations. Consequently, the term $E_{f}\left[\log _{2}(f)\right]$ called the self-information of $f$ cannot be calculated. However, the second term, $-E_{f}\left[\log _{2}(g)\right]$, can still be approximated via the observations. This approximation is the negative average sample log-likelihood, noted LLH and defined by:

$\operatorname{LLH}(g, \mathbf{x}):=-\frac{1}{N} \sum_{i=1}^{N} \log _{2}\left(g\left(x_{i}\right)\right)$

where $\mathbf{x}=\left\{x_{i}\right\}, i=1, \ldots, N$ are the empirical data and $g\left(x_{i}\right)$ is the likelihood that model $g$ has produced the observation $x_{i}$. In the case of GMPE selection, $g$ is the probability density function given by a GMPE to predict the observation produced by an earthquake defined by a magnitude $M$ (and by other characteristics such as the style of faulting) at a site $i$ that is located at a distance $R$ from the source.

We used the LLH divergence as a criterion to rank the candidate GMPEs. Due to its negative sign, the negative average sample log-likelihood is not a measure of closeness but a measure of the distance between a model and the data-generating process. A small LLH indicates that the candidate model is close to the process that has generated the data while a large LLH corresponds to a model that is less likely of having generated the data.

In order to interpret the rankings, weights obtained from the LLH values were compared to the uniform weight $w_{\text {unif }}=\frac{1}{M}$, where $M$ is the number of GMPEs. This comparison tells us to what degree the data support or reject a model with respect to the state of non-informativeness. It is expressed by the data support index (DSI) which gives the percentage by which the weight of a model is increased (positive DSI) or decreased (negative DSI) by data. The DSI of model $g_{i}$ with LLH-value based weight $w_{i}$ is:

$\operatorname{DSI}_{i}=100 \frac{w_{i}-w_{\text {unif }}}{w_{\text {unif }}}$, where

$w_{i}=\frac{2^{-\operatorname{LLH}\left(g_{i}, \mathbf{x}\right)}}{\sum_{k=1}^{K} 2^{-\operatorname{LLH}\left(g_{k}, \mathbf{x}\right)}}$

This ranking method has been recently used by Delavaud et al. (2012) to test the global applicability of GMPEs for active shallow crustal regions. The LLH divergence was computed for 11 GMPEs for different regions and magnitude and distance ranges to assess their validity domain.

The LLH-based weights defined by Eq. 4 cannot be automatically regarded as probabilities as the LLH values are independently determined for each model (Kolmogorov's axioms of mutual exclusiveness and collective exhaustiveness are not respected) and only subsequently made to sum up to one (see Scherbaum and Kühn 2011, for more details about this subject). Therefore, we advise not to directly use them as logic tree weights but to use them in combination with expert judgment. The purpose of using empirical data was not to replace expert judgment but rather to help the judgment process by providing additional information about the applicability of GMPEs, especially in regions where no indigenous model exists.

Although the amount of empirical groundmotion data is rapidly increasing worldwide, we faced some limitations while testing GMPEs with the compiled data. We considered the distribution of empirical ground-motion data in terms of magnitude and distance. We also accounted for the reduction in available data size in terms of their usable period range in order to reduce the filter cutoff influence on the spectral ordinates. The country-based distribution of the data was also considered to examine the similarities between the original datasets of the tested GMPEs and our database used for testing these GMPEs because we wanted to prevent biased evaluations due to similarities between our dataset and those of the GMPEs. A homogenous dataset was not available for SCR, and therefore, no tests for this tectonic regime were made.

For subduction zones, we had available a restricted dataset that only consisted of inslab strikeslip earthquakes along the Hellenic arc with a total number of 65 recordings. Moment magnitudes of SZ data range from 5.2 to 6.7 , their depth mainly varies from 40 to $90 \mathrm{~km}$, and the hypocentral 
Table 5 Ranking of the candidate GMPEs for subduction zones based on LLH values for PSA at 0.05, 0.3, 0.5, 0.8, 1, 1.5 , and $2 \mathrm{~s}$

\begin{tabular}{lccl}
\hline \multicolumn{3}{l}{ Subduction zones-PSA 0.05 to $2 \mathrm{~s}$} \\
\hline Rank & LLH & DSI & Model \\
\hline 1 & 1.979 & 29.57 & Lin and Lee (2008) \\
2 & 1.988 & 28.76 & Zhao et al. (2006) \\
3 & 2.206 & 10.71 & Youngs et al. (1997) \\
4 & 2.499 & -9.641 & Kanno et al. (2006) \\
5 & 2.500 & -9.704 & McVerry et al. (2006) \\
6 & 3.344 & -49.70 & Atkinson and Boore (2003) \\
\hline
\end{tabular}

distances are mostly from 70 to $300 \mathrm{~km}$. All the GMPEs from Table 3 have been tested against this Greek dataset except for the models of Atkinson and Macias (2009) and Garcia et al. (2005). The former model only considers interface events with magnitudes greater than 7.5 whereas the latter model is only derived for inslab earthquakes and hence its applicability for PSHA is limited. None of the tested GMPEs used Greek data for their derivations. Rankings have been performed for pseudo-spectral accelerations (PSAs) at spectral periods between 0.05 and $2 \mathrm{~s}$. Table 5 shows the ranking using the chosen spectral periods. The first two models in the ranking are the models of Lin and Lee (2008) and Zhao et al. (2006). These modes were derived from the data pertaining to northern Taiwan and Japan, respectively. They are equally supported by the Greek data with a DSI of about $29 \%$ each. On contrary, the global model of Atkinson and Boore (2003) appears particularly inconsistent with the present Greek dataset with a DSI of about $-50 \%$. The Atkinson and Boore (2003) model was sensitive to the changes in the period range considered as it predicted the Greek ground motions fairly well for periods below $0.16 \mathrm{~s}$. The overall results of the testing for subduction zones are summarized in Table 9 under the Category based on datatesting results. They are presented in more detail in Beauval et al. (2012).

For active shallow crustal regions, we considered two databases that are composed of recordings from Europe (DB1) and from other ASCR around the world (DB2). The majority of recordings in DB1 are in the magnitude and distance range: $4<M_{\mathrm{w}}<7$ and $1 \mathrm{~km}<\mathrm{RJB}<200 \mathrm{~km}$,
Fig. 3 Distribution of the database DB1 (European database) in terms of Joyner-Boore distance (RJB) and magnitude. For illustrative purposes, the recordings with $\mathrm{RJB}<0.1 \mathrm{~km}$ are plotted as $0.1 \mathrm{~km}$

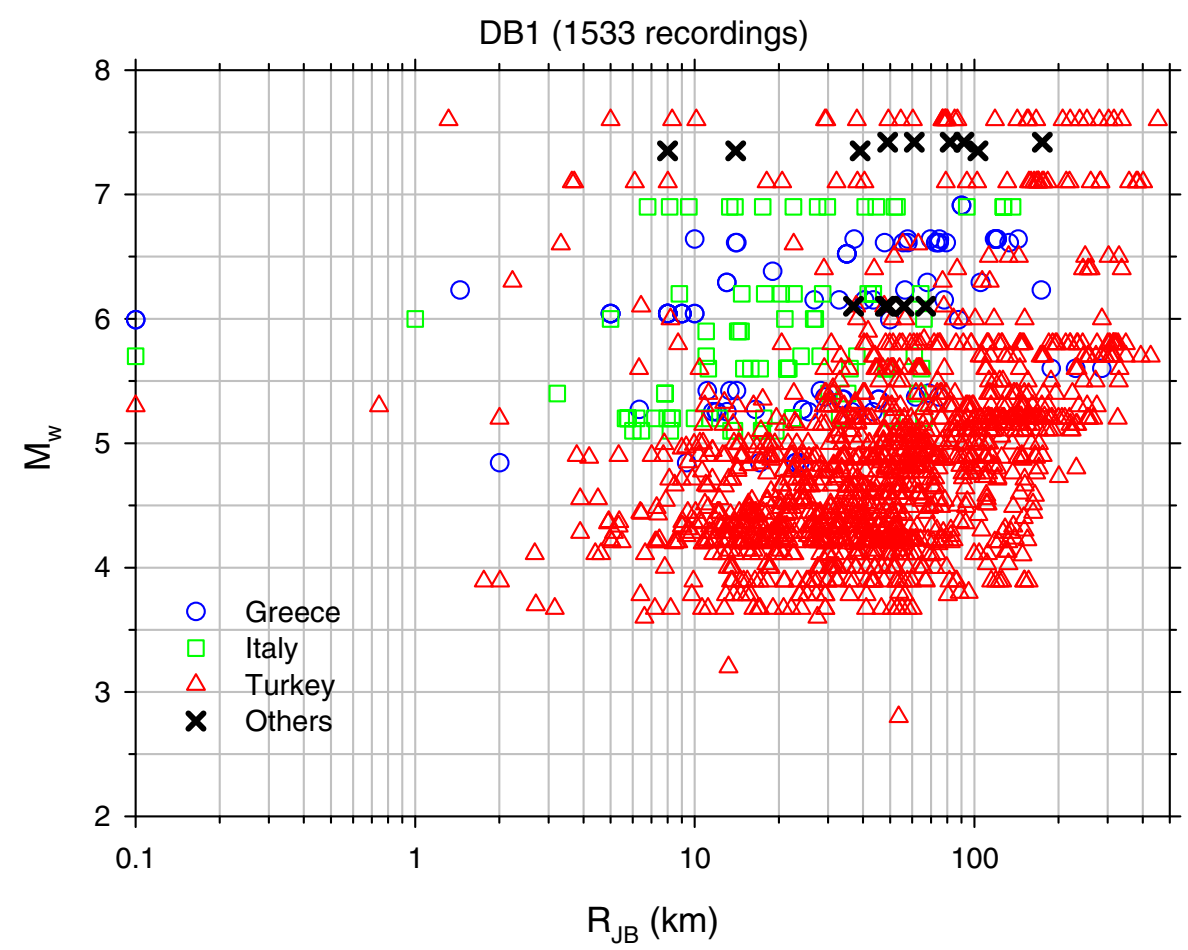


Fig. 4 Distribution of the database DB2

(Non-European database) in terms of Joyner-Boore distance (RJB) and magnitude. For illustrative purposes, the recordings with $\mathrm{RJB}<0.1 \mathrm{~km}$ are plotted as $0.1 \mathrm{~km}$

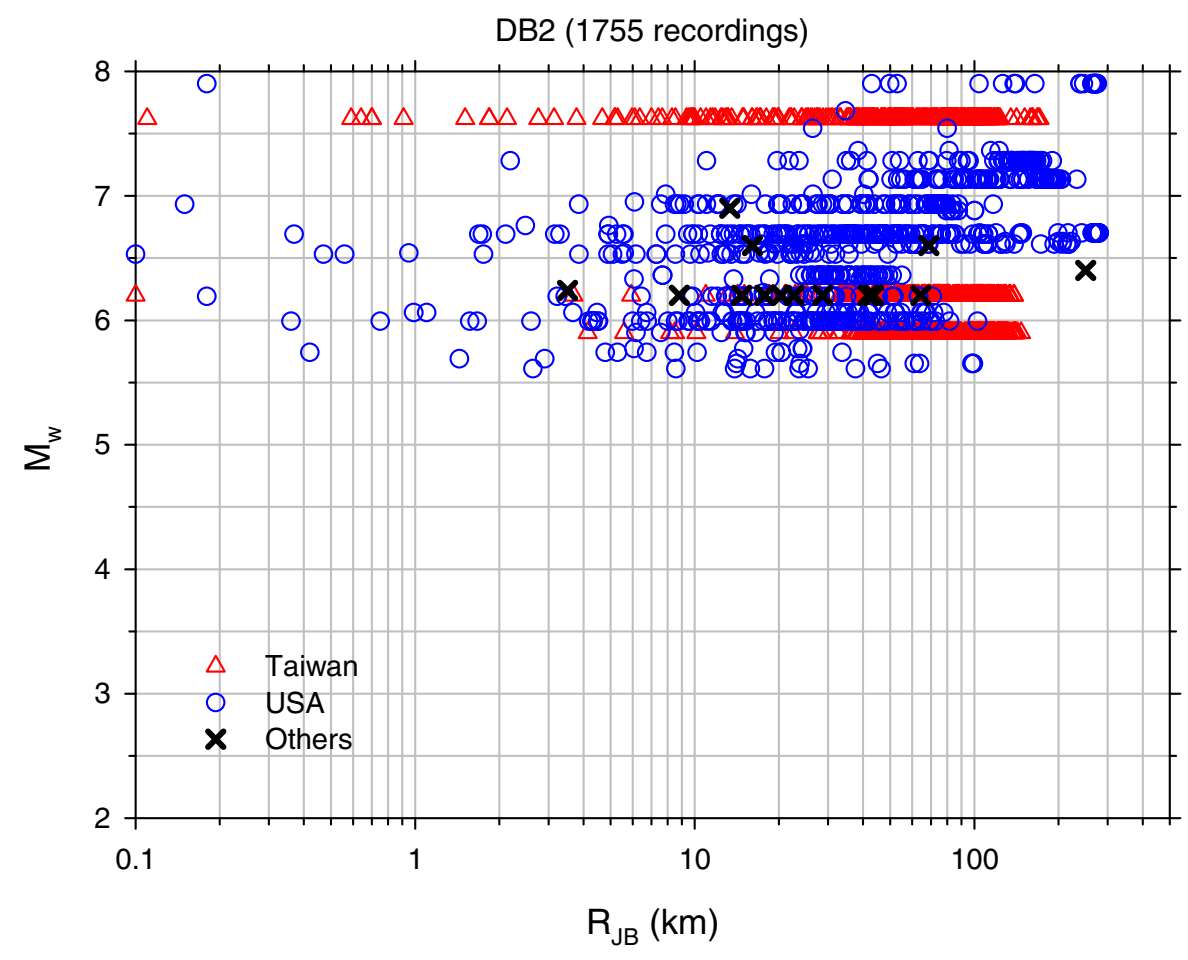

respectively. Due to the lack of large magnitude events in DB1, GMPEs were also tested against DB2 which is mainly composed of magnitudes between 6 and 8 . The main assumption while running these analyses was the weak regional dependence of GMPEs. Both databases were extracted from the SHARE strong-motion databank (Akkar et al. 2010) that is compiled from various original databases (Ambraseys et al. 2004; Luzi et al. 2008; Chiou et al. 2008; Cotton et al. 2008; Sandikkaya et al. 2010). The European dataset is presented in Fig. 3. It contains 1,533 recordings, mainly from Turkey. The major reason for the larger number of Turkish recordings is the fact that the other European databases do not contain site classification in terms of $v_{\mathrm{S} 30}$ and lack complete information on
Table 6 Ranking of the candidate GMPEs for ASCR based on LLH values for PSA at $0.1,0.2$, $0.5,1$, and $2 \mathrm{~s}$ from DB1 (European database)

\begin{tabular}{llll}
\hline \multicolumn{4}{l}{ Active shallow crustal regions-DB1-PSA 0.1 to 2 s } \\
\hline Rank & LLH & DSI & Model \\
\hline 1 & 2.378 & 68.29 & Bindi et al. (2010) \\
2 & 2.396 & 66.20 & Cauzzi and Faccioli (2008) \\
3 & 2.427 & 62.67 & Cotton et al. (2008) \\
4 & 2.588 & 45.49 & Akkar and Bommer (2010) \\
5 & 2.680 & 36.50 & Douglas et al. (2006) \\
6 & 2.800 & 25.61 & Zhao et al. (2006) \\
7 & 2.938 & 14.15 & Chiou and Youngs (2008) \\
8 & 3.158 & 1.99 & Ambraseys et al. (2005) \\
9 & 3.271 & -9.38 & Danciu and Tselentis (2008) \\
10 & 3.869 & -40.13 & Abrahamson and Silva (2008) \\
11 & 4.121 & -49.72 & Boore and Atkinson (2008) \\
12 & 4.785 & -68.27 & Campbell and Bozorgnia (2008) \\
13 & 4.921 & -71.12 & Kalkan and Gülkan (2004) \\
14 & 5.332 & -78.28 & Massa et al. (2008) \\
\hline
\end{tabular}


Table 7 Ranking of the candidate GMPEs for ASCR based on LLH values for PSA at $0.1,0.2$, $0.5,1$, and $2 \mathrm{~s}$ from DB2 (non-European database)

\begin{tabular}{llll}
\multicolumn{4}{l}{ Active shallow crustal regions-DB2-PSA 0.1s to 2s } \\
\hline Rank & LLH & DSI & Model \\
\hline 1 & 1.558 & 29.49 & Akkar and Bommer (2010) \\
2 & 1.592 & 26.43 & Chiou and Youngs (2008) \\
3 & 1.620 & 24.00 & Boore and Atkinson (2008) \\
4 & 1.672 & 19.65 & Abrahamson and Silva (2008) \\
5 & 1.678 & 19.15 & Kalkan and Gülkan (2004) \\
6 & 1.710 & 16.45 & Campbell and Bozorgnia (2008) \\
7 & 1.761 & 12.50 & Bindi et al. (2010) \\
8 & 1.813 & 8.477 & Danciu and Tselentis (2008) \\
9 & 1.835 & 6.81 & Cauzzi and Faccioli (2008) \\
10 & 1.850 & 5.75 & Zhao et al. (2006) \\
11 & 2.331 & -24.25 & Ambraseys et al. (2005) \\
12 & 2.545 & -34.67 & Douglas et al. (2006) \\
13 & 2.897 & -48.82 & Cotton et al. (2008) \\
14 & 3.288 & -60.97 & Massa et al. (2008)
\end{tabular}

some of the distance measures used by the candidate GMPEs. Other observations mostly come from Italy and Greece. The non-European dataset is presented in Fig. 4. It mostly contains recordings from the USA and Taiwan that were extracted from the NGA database. Rankings based on PSAs at five spectral periods $(0.1,0.2,0.5,1$, and $2 \mathrm{~s})$ are presented in Tables 6 and 7 for DB1 and DB2, respectively. A total of 14 GMPEs have been tested: all the models in Table 4 except for the GMPEs of Idriss (2008), Kanno et al. (2006), Özbey et al. (2004), McVerry et al. (2006), and Pankow and Pechmann (2004). The Italian model of Bindi et al. (2010) is ranked first, closely followed by two non-European models, Cauzzi and Faccioli (2008) and Cotton et al. (2008), with DSIs larger than $60 \%$. The testing results of the Akkar and Bommer (2010) model appear to be quite robust as it is well ranked for both datasets DB1 and DB2. The model of Kalkan and Gülkan (2004) and the NGA models are better able to predict ground motions from the large earthquakes that compose DB2 than ground motions from DB1. The results of the data testing for
Table 8 Expert choices and the final logic trees for stable continental regions
Names in bold are the selected models $W S$ weighting scheme

\begin{tabular}{ll}
\hline Category based on expert judgment & Models \\
Models supported by all the experts & Campbell (2003) \\
& Toro et al. (1997) \\
Models chosen by a majority of experts & Atkinson and Boore (2006) \\
& Douglas et al. (2006) \\
Models chosen by a minority of experts & Atkinson (2008) \\
Models not chosen by the experts & \\
Selected models for shield & Tavakoli and Pezeshk (2005) \\
Campbell (2003) & WS \\
Toro (2002, unpublished) & $\mathbf{0 . 5}$ \\
Selected models for continental crust & $\mathbf{0 . 5}$ \\
Campbell (2003) adjusted to $800 ~ \mathbf{~} / \mathbf{s}$ & WS \\
Toro (2002, unpublished) adjusted to $\mathbf{8 0 0 ~} \mathbf{~} / \mathbf{s}$ & $\mathbf{0 . 2}$ \\
Akkar and Bommer (2010) & $\mathbf{0 . 2}$ \\
Cauzzi and Faccioli (2008) & $\mathbf{0 . 2}$ \\
Chiou and Youngs (2008) & $\mathbf{0 . 2}$ \\
\hline & $\mathbf{0 . 2}$ \\
\hline
\end{tabular}


active shallow crustal regions are summarized in Table 10 under the Category based on data-testing results.

\section{Ground-motion logic tree}

Based on the results of both the expert judgment and the testing, a consensus set of GMPEs was determined for each tectonic regime. Tables 8, 9, and 10 were used to guide the selection, especially when expert judgment and empirical data testing results were available. Models supported by the empirical data testing and the experts' choices (first category) were selected while the models that were not supported by the data testing and not chosen by the experts (fourth category) have been rejected. For the rest of the models (second and third categories), discussions were held between the experts and ground-motion model- ing group to decide on their rejection or selection. Weights were also determined but different propositions were retained for sensitivity analyses.

For stable continental regions, for which no testing could be performed due to a lack of data, a distinction between shield and continental crust was taken into account. For shields, the two models supported by all the experts were selected with equal weights: Toro's (2002, unpublished) model which is an updated version of Toro et al. (1997) and the model by Campbell (2003). For continental crust, three GMPEs for ASCR were adopted (Akkar and Bommer 2010; Cauzzi and Faccioli 2008; Chiou and Youngs 2008) in addition to the models of Toro (2002, unpublished) and Campbell (2003). This accounts for uncertainty in knowing if ground motions in continental crust are more like those in ASCR or in SCR. Equal weights were assigned to the five GMPEs selected for continental crust. The Toro (2002, unpublished)
Table 9 Expert choices, data-based testing results, and logic trees for subduction zones
Names in bold are the selected models. The preferred WS is shown in bold $W S$ weighting scheme

\begin{tabular}{|c|c|c|}
\hline Category based on expert judgment & \multicolumn{2}{|c|}{ Models } \\
\hline Models supported by all the experts & \multicolumn{2}{|c|}{ Atkinson and Boore (2003) } \\
\hline Models supported by a majority of experts & \multicolumn{2}{|c|}{$\begin{array}{l}\text { Youngs et al. (1997) } \\
\text { Zhao et al. (2006) }\end{array}$} \\
\hline Category based on data-testing results & \multicolumn{2}{|c|}{ Models } \\
\hline $\begin{array}{l}\text { Models supported by the testing } \\
\text { for long periods }(T>0.16 \mathrm{~s})\end{array}$ & \multicolumn{2}{|c|}{$\begin{array}{l}\text { Lin and Lee (2008) } \\
\text { Zhao et al. (2006) }\end{array}$} \\
\hline $\begin{array}{l}\text { Models supported by the testing } \\
\text { for short periods }(T \leq 0.16 \mathrm{~s})\end{array}$ & \multicolumn{2}{|c|}{$\begin{array}{l}\text { Atkinson and Boore (2003) } \\
\text { Zhao et al. (2006) }\end{array}$} \\
\hline $\begin{array}{l}\text { Category based on expert judgment } \\
\text { and data-testing results }\end{array}$ & \multicolumn{2}{|c|}{ Models } \\
\hline \multicolumn{3}{|l|}{$\begin{array}{l}\text { Models supported by the data testing } \\
\text { and the experts choices }\end{array}$} \\
\hline $\begin{array}{l}\text { Models chosen by a majority } \\
\text { of experts and supported } \\
\text { by the data-testing results }\end{array}$ & \multicolumn{2}{|c|}{ Zhao et al. (2006) } \\
\hline $\begin{array}{l}\text { Models chosen by a minority } \\
\text { of experts or with a low } \\
\text { data-testing result }\end{array}$ & \multicolumn{2}{|c|}{$\begin{array}{l}\text { McVerry et al. (2006 } \\
\text { Atkinson and Macia } \\
\text { Garcia et al. (2005) }\end{array}$} \\
\hline \multicolumn{3}{|l|}{$\begin{array}{l}\text { Models not supported by the data-testing } \\
\text { and not chosen by the experts }\end{array}$} \\
\hline Selected models & WS1 & WS2 \\
\hline Zhao et al. (2006) & 0.4 & 0.25 \\
\hline Atkinson and Boore (2003) & 0.2 & 0.25 \\
\hline Youngs et al. (1997) & 0.2 & 0.25 \\
\hline Lin and Lee (2008) & 0.2 & 0.25 \\
\hline
\end{tabular}


Table 10 Expert choices, data-based testing results, and logic trees for active shallow crustal regions
Names in bold are the selected models. The preferred WS is shown in bold

WS weighting scheme
Category based on expert judgment
Models supported by all the experts

Models supported by a majority of experts

Category based on data-testing results

Models supported by the testing (European dataset)

Models supported by the testing

(non-European dataset)

Category based on expert judgment and data-testing results

Models supported by the data testing and by the experts choices

Models chosen by a majority of experts and supported by the data-testing results

Models chosen by a minority of experts or with a low data-testing result

Models not supported by the data testing and not chosen by the experts
Models

Boore and Atkinson (2008)

Akkar and Bommer (2010)

Cauzzi and Faccioli (2008)

Zhao et al. (2006)

Models

Bindi et al. (2010)

Cauzzi and Faccioli (2008)

Akkar and Bommer (2010) Chiou and Youngs (2008)

Models

\begin{abstract}
Akkar and Bommer (2010) Cauzzi and Faccioli (2008)
\end{abstract}

Abrahamson and Silva (2008)

Ambraseys et al. (2005)

Campbell and Bozorgnia (2008)

Idriss (2008)

McVerry et al. (2006)

Pankow and Pechmann (2004)

Kalkan and Gülkan (2004)

Danciu and Tselentis (2008)

Massa et al. (2008)

Selected models for periods $T \leq 3 \mathrm{~s}$

WS1 WS2

WS3

WS4 WS5

WS6 WS7

Akkar and Bommer (2010)

$\begin{array}{llllll}0.30 & 0.30 & 0.40 & 0.25 & 0.30\end{array}$

Cauzzi and Faccioli (2008)

$\begin{array}{llll}0.30 & 0.20 & 0.20 & 0.25\end{array}$

0.25

0.35 0.10

Zhao et al. (2006)

0.20

$\begin{array}{lll}0.20 & 0.20 & 0.25\end{array}$

0.20

$\mathbf{0 . 3 5} 0.40$

Chiou and Youngs (2008)

0.20

0.30

0.2

0.25

0.25

0.10 0.10

Selected models for periods $3 \mathrm{~s}<T \leq 10 \mathrm{~s}$

Cauzzi and Faccioli (2008)

Chiou and Youngs (2008)
0.5

0.5 and Campbell (2003) models were decided to be adjusted for the generic rock site condition in Europe, established within the framework of SHARE project that is described with a shearwave velocity of $v_{\text {rock }}=800 \mathrm{~m} / \mathrm{s}$ and $\kappa=0.03$ following Van Houtte et al. (2011). The proposed weighting scheme for SCR is presented in Table 8 .

For subduction zones (Table 9), the results of the empirical data testing and the choices of the experts were quite divergent. Only the model of Zhao et al. (2006) was supported by the majority of experts and the data-testing results. This model has been selected. The McVerry et al. (2006) model was neither supported by the experts nor the empirical data testing, and consequentially, it was rejected. The models of Atkinson and Boore (2003) and Youngs et al. (1997) that were the consensus selection of the experts as well as the Lin and Lee (2008) and Zhao et al. (2006) models that were ranked the best in the testing were considered in the weighting scheme. A weight of 0.4 was assigned to the Zhao et al. (2006) model whereas the other three models were weighted equally with 0.2 . An other weighting scheme where the four selected GMPEs have equal weights has been proposed. We decided to make a sensitivity study to investigate the differences between the two weighting schemes. No difference in weights 
Table 11 Weighting scheme (WS) for active regions in oceanic crust (same as for ASCR). The preferred WS is shown in bold

\begin{tabular}{llllllll}
\hline Selected models for periods $T \leq 3 \mathrm{~s}$ & WS1 & WS2 & WS3 & WS4 & WS5 & WS6 & WS7 \\
Akkar and Bommer (2010) & 0.30 & 0.30 & 0.40 & 0.25 & 0.30 & $\mathbf{0 . 3 5}$ & 0.10 \\
Cauzzi and Faccioli (2008) & 0.30 & 0.20 & 0.20 & 0.25 & 0.25 & $\mathbf{0 . 3 5}$ & 0.40 \\
Zhao et al. (2006) & 0.20 & 0.20 & 0.20 & 0.25 & 0.20 & $\mathbf{0 . 1 0}$ & 0.10 \\
Chiou and Youngs (2008) & 0.20 & 0.30 & 0.20 & 0.25 & 0.25 & $\mathbf{0 . 2 0}$ & 0.40 \\
Selected models for periods $3 \mathrm{~s}<T \leq 10 \mathrm{~s}$ & WS & & & & & & \\
Cauzzi and Faccioli (2008) & $\mathbf{0 . 5}$ & & & & & & \\
Chiou and Youngs (2008) & $\mathbf{0 . 5}$ & & & & & & \\
\hline
\end{tabular}

between interface and inslab earthquakes was made, due to a lack of data. However, this may be a critical issue in PSHA, and further research is needed in the future. The proposed weighting schemes are presented in Table 9.

For active shallow crustal regions (Table 10), two models were supported by both the experts and the empirical data testing: the models of Akkar and Bommer (2010) and Cauzzi and Faccioli (2008). These models were directly considered in the logic tree weighting scheme. In addition, we selected two other models: the Zhao et al. (2006) model, which was favored by the majority of the experts, and the NGA model of Chiou and Youngs (2008), which was supported by the testing using non-European recordings. This selection is in agreement with the recent study conducted by Delavaud et al. (2012) to test the global applicability of GMPEs using the global dataset of Allen and Wald (2009). For PGA and PSA at $1 \mathrm{~Hz}$ in Europe and the Middle East, the four best-ranked models according to Delavaud et al. (2012) are the models of Akkar and Bommer (2010), Chiou et al. (2010), Cauzzi and Faccioli (2008), and Berge-Thierry et al. (2003) that are followed by the models of Chiou and Youngs (2008) and Zhao et al. (2006). Note that the model of Chiou et al. (2010) is an extension of the Chiou and Youngs (2008) model for small-to-moderate magnitudes. It is consistent with the Chiou and Youngs (2008) model for large magnitudes $\left(M_{\mathrm{w}} \geq 6\right)$ but has new coefficients for smaller magnitudes. This result suggests that Delavaud et al. (2012) would have ranked first the four models that we selected for ASCR if they had not considered the model of Chiou et al. (2010) and the model of Berge-Thierry et al. (2003). The model of Chiou et al. (2010) was not published when we started the selection of GMPEs. It is also defined only for a limited number of periods. We considered moreover that the model of Berge-Thierry et al. (2003) is obsolete. For longer periods, between 3 and $10 \mathrm{~s}$, only the models of Cauzzi and Faccioli (2008) and Chiou and Youngs (2008) were selected and given equal weights $(0.5)$ because the Akkar and Bommer (2010) and Zhao et al. (2006) models are not defined for periods up to $10 \mathrm{~s}$. For periods lower than $3 \mathrm{~s}$, different weighting schemes have been proposed, as shown in Table 10. The weighting scheme WS6 was, however, preferred that assigns higher weights to the two models that are supported by both the experts and the empirical data testing. It was also decided to make a sensitivity analysis to better understand the influence of the weights on the computed hazard.

For active regions in oceanic crust, GMPEs from ASCR were chosen (Table 11). For areas of deep focus non-subduction earthquakes, such as Vrancea (Romania) or the Betics (Spain), we decided to use the GMPEs selected for subduction instead of the empirical model of Sokolov et al. (2008), which is directly derived from the recordings of Vrancea. The model by Sokolov et al. (2008) is too complex for regional PSHA because it models azimuthal variations of ground motion (Table 12). Finally, for volcanic zones,

Table 12 Weighting scheme for Vrancea (same as for SZ)

\begin{tabular}{lll}
\hline Selected models & WS1 & WS2 \\
\hline Zhao et al. (2006) & $\mathbf{0 . 4}$ & 0.25 \\
Atkinson and Boore (2003) & $\mathbf{0 . 2}$ & 0.25 \\
Youngs et al. (1997) & $\mathbf{0 . 2}$ & 0.25 \\
Lin and Lee (2008) & $\mathbf{0 . 2}$ & 0.25 \\
\hline
\end{tabular}

The preferred WS is shown in bold $W S$ weighting scheme 
Table 13 Weighting scheme (WS) for volcanic zones

\begin{tabular}{ll}
\hline Selected models & WS \\
\hline Faccioli et al. (2010) & $\mathbf{1}$ \\
\hline
\end{tabular}

it was decided to adopt an approach similar to that implemented in Italy when creating the currently applied set of seismic hazard maps (see Montaldo et al. 2005) rather than using the model of McVerry et al. (2006), which only seeks to model higher attenuation in volcanic zones rather than ground motions from volcanorelated events. This approach consists of introducing separate GMPEs within a seismic source zone of limited extension surrounding a volcano with well-documented historical evidence of damaging earthquakes, such as the Mount Etna volcano, in Sicily. Such GMPEs should be able to deal with events of shallow focal depth, from 2 to $5 \mathrm{~km}$. An analysis expressly carried out on acceleration records from recent moderate earthquakes $\left(3.2<M_{\mathrm{w}}<4.5\right)$ of recent years in Italy, notably in the Mount Amiata (southern Tuscany) and Mount Etna areas, has shown that the use of the recent attenuation model of Faccioli et al. (2010) was appropriate, and its adoption was therefore agreed to by WP4 of SHARE (Table 13).

With logic trees containing between two and five GMPEs for each tectonic regimes (except for volcanic zones), the SHARE WP4 group aimed at better taking epistemic uncertainties into account. In comparison, for the SESAME project which provided the first homogeneous assessment of seismic hazard for the whole Mediterranean region, only three GMPEs were considered: the model of Ambraseys et al. (1996) for all crustal sources, the model of Musson (1999) for Vrancea, and the model of Papaioannou and Papazachos (2000) for intermediate-depth seismic activity sources in the Hellenic Arc (Jiménez et al. 2001).

\section{Sensitivity analysis}

Logic tree and sensitivity analyses are generally run simultaneously. The results of a preliminary sensitivity analysis usually offer guidance for an iterative revision of the final logic tree structure (Scherbaum et al. 2005; Bommer and Scherbaum 2008). As different weighting schemes were pro-
Table 14 Percentage differences for ASCR for three ground-motion intensity measure types, two seismic source types, and two return periods. The maximum for each ground-motion intensity measure type, source type, and return period is highlighted in bold

\begin{tabular}{|c|c|c|c|c|}
\hline \multirow[t]{2}{*}{ Weighting schemes } & \multicolumn{2}{|l|}{ Area source } & \multicolumn{2}{|l|}{ Fault source } \\
\hline & 475 years $(\%)$ & 2,475 years $(\%)$ & 475 years $(\%)$ & 2,475 years $(\%)$ \\
\hline \multicolumn{5}{|l|}{ PGA } \\
\hline Preferred WS vs. WS1 & 3.27 & 3.36 & 4.22 & 3.97 \\
\hline Preferred WS vs. WS2 & $(+) 7.68$ & 5.95 & 5.38 & 5.88 \\
\hline Preferred WS vs. WS3 & 6.96 & 5.20 & 7.82 & 6.66 \\
\hline Preferred WS vs. WS4 & 6.39 & 5.43 & 5.79 & 5.10 \\
\hline Preferred WS vs. WS5 & 5.45 & 4.33 & 4.57 & 4.25 \\
\hline Preferred WS vs. WS7 & 4.44 & $(-) 6.49$ & $(-) 8.59$ & $(-) 9.51$ \\
\hline \multicolumn{5}{|l|}{ PSA $(0.2 \mathrm{~s})$} \\
\hline Preferred WS vs. WS1 & 3.28 & 3.55 & 4.21 & 4.60 \\
\hline Preferred WS vs. WS2 & 7.80 & 6.84 & 6.42 & 5.79 \\
\hline Preferred WS vs. WS3 & 8.93 & 7.86 & 10.71 & 9.78 \\
\hline Preferred WS vs. WS4 & 5.91 & 6.00 & 5.63 & 5.87 \\
\hline Preferred WS vs. WS5 & 5.49 & 5.12 & 5.07 & 5.02 \\
\hline Preferred WS vs. WS7 & $(-) 11.04$ & $(-) 8.83$ & $(-) 14.57$ & $(-) 14.26$ \\
\hline \multicolumn{5}{|l|}{ PSA (1s) } \\
\hline Preferred WS vs. WS1 & 3.53 & 4.49 & 3.31 & 4.34 \\
\hline Preferred WS vs. WS2 & 3.59 & 7.31 & 2.65 & 6.38 \\
\hline Preferred WS vs. WS3 & 3.73 & 7.35 & 2.48 & 4.56 \\
\hline Preferred WS vs. WS4 & 4.68 & $(-) 7.50$ & 4.72 & 7.46 \\
\hline Preferred WS vs. WS5 & 3.02 & 5.89 & 2.88 & 5.32 \\
\hline Preferred WS vs. WS7 & $(+) 4.95$ & 4.60 & $(-) 5.88$ & $(-) 7.48$ \\
\hline
\end{tabular}


posed for SZ and ASCR, a sensitivity analysis was necessary to explore the impact of the assigned weights on the final hazard results. We briefly report the main results of this analysis and refer to Danciu (submitted for publication) for more details.

The sensitivity analysis was performed by considering the selected GMPEs for each tectonic regime (as presented in Tables 9 and 10) and a set of fictitious seismic sources. Two types of seismic sources were considered: an area source zone (ASZ) and a FS. A fictitious ASZ was used to simulate the seismicity in an ASCR and also on subduction intraslab sources. A virtual FS was used to model an active shallow crustal fault as well as a subduction interface source.

Four ground-motion intensity measures were considered: peak ground acceleration, PGV, and pseudo-acceleration spectra at the spectral periods of 0.2 and $1.0 \mathrm{~s}$. Seismic hazard maps for each weighting scheme were obtained for two reference return periods: 475 and 2,475 years, the former corresponding to $10 \%$ probability of exceedance in 50 years and the latter indicating a $2 \%$ probability of exceedance in 50 years. Additionally, individual hazard maps for each GMPE were produced. All the resulting hazard maps were estimated for a reference rock site, defined by $v_{\mathrm{S} 30}=800 \mathrm{~m} / \mathrm{s}$. The seismic hazard software (Pagani et al. 2010) developed within the prototype of GEM, namely the GEM1 project, was used for the calculations. Details of the source characterization and hazard calculation settings are presented in more detail in Danciu (submitted for publication).

The difference between the hazard maps of the preferred weighting schemes and those com- puted from alternative weights was quantified by the mean of the percentage differences. Percentage difference for each grid point was computed by:

$$
\operatorname{PerDiff}(\%)=\frac{\mathrm{WS}_{(\text {proposed })}-\mathrm{WS}_{(\text {preferred })}}{\mathrm{WS}_{(\text {preferred })}} \times 100
$$

where $\mathrm{WS}_{\text {(preferred) }}$ are the estimated expected ground motion at each grid point from the preferred weighting scheme and $\mathrm{WS}_{\text {(proposed) }}$ contains the values using the alternative weighting schemes. For example, for active crustal regions, the preferred weighting scheme is WS6 and the alternative weighting schemes are WS1, WS2, WS3, WS4, WS5, and WS7 as reported in Table 10. Maps showing the percentage difference were produced for all ground-motion intensity measures and for the specified return periods. Due to the limited space, the percentage difference maps are not reproduced herein, but a summary of the percentage differences for PGA, PSA (0.2 s), and PSA (1 s) for different weighting schemes is shown in Table 14 for ASCR and in Table 15 for SZ.

For ASCR, the sensitivity analysis shows that the absolute difference between the preferred and the proposed weighting schemes varies within the range of $5 \%$ to $10 \%$ for the ASZ and $5 \%$ to $15 \%$ for the FS. Most of the differences occur when the proposed weighting scheme WS7 is compared with the preferred one (WS6). The examination of individual hazard maps for each selected GMPE suggest that the equations proposed by Akkar and Bommer (2010) and Chiou and Youngs (2008) dominate the hazard in the areal zones of active shallow crustal tectonic

Table 15 Percentage difference values for SZ for three ground-motion intensity measure types, two seismic source types, and two return periods

\begin{tabular}{llllll}
\hline Weighting schemes & \multicolumn{3}{l}{ Subduction inslab } & & \multicolumn{2}{l}{ Subduction interface } \\
\cline { 2 - 3 } & 475 years $(\%)$ & 2,475 years $(\%)$ & & 475 years $(\%)$ & 2,475 years $(\%)$ \\
\hline PGA & $\begin{array}{l}\text { Preferred WS vs. WS2 } \\
\text { PSA (0.2s) }\end{array}$ & $\mathbf{( - ) 8 . 8 0}$ & 6.81 & 6.87 & $\mathbf{( - ) 6 . 9 7}$ \\
$\begin{array}{l}\text { Preferred WS vs. WS2 } \\
\quad \text { Preferred WS vs. WS2 }\end{array}$ & $\mathbf{( - ) 8 . 7 0}$ & 8.51 & 6.83 & $\mathbf{( - ) 8 . 0 0}$ \\
\hline
\end{tabular}

The maximum for each source type and return period is highlighted in bold 
regimes because they yield higher values when compared to the other remaining two GMPEs (roughly 30\% larger). Cauzzi and Faccioli (2008) and Chiou and Youngs (2008) predict larger ground motions in shallow crustal fault sources (roughly 60\% larger than the other two GMPEs), thus dominating the hazard for such cases.

In the case of subduction zone, the percentage difference varies between $4 \%$ and $10 \%$. The differences decrease with increasing period values for subduction inslab sources. Contrary to this observation, the hazard differences become larger as the vibration period increases for subduction interface cases. By contrast, for subduction interface sources, the difference increases as the return periods increase. Zhao et al. (2006) and Youngs et al. (1997) were found to be responsible for the larger values in the seismic hazard for the subduction sources (predicting roughly six times larger ground motions than the other two GMPEs).

The overall results of the sensitivity analysis on different weighting schemes suggest that for the considered seismic sources, there is a moderate impact on the hazard results. Sabetta et al. (2005) also concluded that if four or more GMPEs are used in the logic tree, the assigned weights do not significantly affect the hazard results. Scherbaum et al. (2005) also indicated that the selection of the GMPEs seems to be more important than the choice of weighting strategy. In essence, the practical conclusion of this preliminary sensitivity analysis led us to keep the present structure of the ground-motion logic tree together with the preferred weights.

\section{Conclusions}

Although it is now common practice to treat uncertainty in ground-motion prediction with a logic tree approach, there is no standard procedure that describes how the tree should be constructed. In this paper, we shared our experience on this subject by presenting the strategy that was adopted to build a logic tree for Europe within the SHARE project. This task involved roughly a dozen institutions with the goal, in a limited amount of time (18 months), to commonly define a logic tree that would capture the center, body, and range of ground motion in six different tectonic regimes in the Euro-Mediterranean region.

The principal idea that guided our strategy was to gather as much knowledge as possible from independent sources and different methods. Based on the characteristics of the available GMPEs determined by Douglas (2008), recently updated by Douglas (2011), we first identified the best candidates using the rejection criteria of Cotton et al. (2006) and Bommer et al. (2010). Afterward, expert judgment highlighted the sets of GMPEs that were, according to the experts, capable of capturing epistemic uncertainties, while testing using observational data showed GMPEs capable of closely predicting past ground motions. The integration of these different approaches was undertaken to propose logic trees that were then subjected to a sensitivity analysis to see the impact on the seismic hazard.

From this experience, we have learnt lessons and identified weaknesses in our methodology. First, a great effort should be dedicated to the collection of data and meta-data in order to get as much information as possible from the GMPE testing. In our case, data were not sufficient to cover the center, body, and range of ground motions in Europe. Secondly, the procedure for the selection and weighting of GMPEs by experts should be clearly defined. Within the SHARE project, most experts required more guidance and information (e.g., What do weights represent? How will they be used afterward?). Selecting GMPEs and assigning weights is still not an obvious task, although Scherbaum and Kühn (2011) have recently proposed a method. To build a logic tree is not to give a quality measure to each candidate GMPE independently from the others but rather to identify the set of models that together, with a certain weighting, can capture the perceived epistemic uncertainty. In the context of the SHARE project that covers a large area, the set of GMPEs had to be the smallest one.

The robustness of the proposed logic tree is a crucial property. For ASCR, the SHARE GMPE selection is in agreement with the data testing of Delavaud et al. (2012) who used an independent dataset to rank candidate GMPEs for Europe and Middle East. Their study also showed that for this 
particular dataset, the recent model of Chiou et al. (2010) but also the model of Berge-Thierry et al. (2003) were both able to predict ground motion in Europe and Middle East reasonably well. Regular updates of the logic tree should be planned to take new data and new GMPEs into account.

Each project is unique and it is important to be aware of its particularities. However, we think that the procedure described above is reproducible and that at least it contributed to the reflections on the way a logic tree for groundmotion prediction should be built.

Acknowledgements The main part of this work has been funded by the EC-Research Framework programme FP7, Seismic Hazard Harmonization in Europe, contract number 226967. The authors would like to warmly thank Julian Bommer, Hilmar Bungum, and Fabian Bonilla for their expert role and their key contribution to the groundmotion prediction equation evaluation and weighting. We thank an anonymous reviewer and Jochen Woessner for their comments on the first draft of this article. This paper also benefited from the feedbacks and interaction with Donat Fäh, Ben Edwards, Marco Pagani, Kyriazis Pitilakis, Pierre-Yves Bard, and Carola Di Alessandro. This work strongly benefited from the constant support of Jochen Woessner and Domenico Giardini, manager and coordinator of the SHARE FP7 project.

\section{References}

Abrahamson NA, Shedlock KM (1997) Overview. Seismol Res Lett 68:9-23

Abrahamson NA, Silva WJ (2008) Summary of the Abrahamson \& Silva NGA ground motion relations. Earthq Spectra 24:67-97

Akkar S, Bommer JJ (2010) Empirical equations for the prediction of PGA, PGV, and spectral accelerations in Europe, the Mediterranean Region, and the Middle East. Seismol Res Lett 81:195-206

Akkar S, Çağnan Z, Yenier E, Erdoğan Ö, Sandikkaya MA, Gülkan P (2010) The recently compiled Turkish strong-motion database: preliminary investigation for seismological parameters. J Seismol 14:457-479

Allen TI, Wald DJ (2009) Evaluation of ground-motion modeling techniques for use in global shakemapa critique of instrumental ground-motion prediction equations, peak ground motion to macroseismic intensity conversions, and macroseismic intensity predictions in different tectonic settings. US Geological Survey Open-File Report 2009-1047, p 114

Ambraseys N, Smit P, Douglas J, Margaris B, Sigbjornsson R, Olafsson S, Suhadolc P, Costa G (2004) Internetsite for European strong-motion data. Boll Geofis Teor Appl 45:113-129
Ambraseys NN, Simpson KA, Bommer JJ (1996) Prediction of horizontal response spectra in Europe. Earthquake Eng Struct Dyn 25:371-400

Ambraseys NN, Douglas J, Sarma SK, Smit PM (2005) Equation for the estimation of strong ground motions from shallow crustal earthquakes using data from Europe and the Middle East: horizontal peak ground acceleration and spectral acceleration. Bull Earthquake Eng 3:1-53

Atkinson GM (2008) Ground-motion prediction equations for eastern north America from a referenced empirical approach: implications for epistemic uncertainty. Bull Seismol Soc Am 98:1304-1318

Atkinson GM, Boore DM (2003) Empirical groundmotion relations for subduction zone earthquakes and their application to Cascadia and other regions. Bull Seismol Soc Am 93:1703-1729

Atkinson GM, Boore DM (2006) Earthquake groundmotion prediction equations for eastern north America. Bull Seismol Soc Am 96:2181-2205

Atkinson GM, Macias M (2009) Predicted ground motions for great interface earthquakes in the Cascadia subduction zone. Bull Seismol Soc Am 99:1552-1578

Atkinson GM, Morrison M (2009) Observations on regional variability in ground-motion amplitudes for small-to-moderate earthquakes in north America. Bull Seismol Soc Am 99:2393-2409

Beauval C, Bard P-Y, Hainzl S, Guéguen P (2008) Can strong motion observations be used to constrain probabilistic seismic hazard estimates? Bull Seismol Soc Am 98:509-520

Beauval C, Theodulidis N, Delavaud E, Cotton F (2012) GMPEs for PSHA calculations: the case of the Greek subduction zone (and other zones around the world). In: Proceedings of the 15 th world conference on earthquake engineering, 24-28 September, Lisbon, Portugal

Berge-Thierry C, Cotton F, Scotti O, Griot-Pommera DA, Fukushima Y (2003) New empirical response spectral attenuation laws for moderate European earthquakes. J Earthquake Eng 7:193-222

Beyer K, Bommer JJ (2006) Relationships between median values and between aleatory variabilities for different definitions of the horizontal component of motion. Bull Seismol Soc Am 96:1512-1522

Bindi D, Luzi L, Massa M, Pacor F (2010) Horizontal and vertical ground motion prediction equations derived from the Italian accelerometric archive (ITACA). Bull Earthquake Eng 8:1209-1230

Bommer JJ, Douglas J, Scherbaum F, Cotton F, Bungum H, Fäh D (2010) On the selection of ground-motion prediction equations for seismic hazard analysis. Seismol Res Lett 81:783-793

Bommer JJ, Douglas J, Strasser FO (2003) Style-of-faulting in ground-motion prediction equations. Bull Earthquake Eng 1:171-203

Bommer JJ, Scherbaum F (2008) The use and misuse of logic-trees in probabilistic seismic hazard analysis. Earthq Spectra 96:1967-1977

Bommer JJ, Stafford PJ, Alarcon JE, Akkar S (2007) The influence of magnitude range on empirical 
ground-motion prediction. Bull Seismol Soc Am 97:2152-2170

Boore DM, Atkinson GM (2008) Ground motion prediction equations for the average horizontal component of PGA, PGV, and 5\%-Damped PSA at spectral periods between $0.01 \mathrm{~s}$ and $10.0 \mathrm{~s}$. Earthq Spectra 24:99138

Budnitz RJ, Apostolakis G, Boore DM, Cluff LS, Coppersmith KJ, Cornell CA, Morris PA (1997) Recommendations for probabilistic seismic hazard analysis: guidance on uncertainty and use of experts, vol 1. NUREG/CR-6372, p 280

Burnham KP, Anderson DR (2002) Model selection and multimodel inference: a practical informationtheoretic approach, 2nd edn. Springer, New York

Campbell KW (2003) Prediction of strong ground motion using the hybrid empirical method and its use in the development of ground-motion (attenuation) relations in eastern north America. Bull Seismol Soc Am 93:1012-1033

Campbell KW, Bozorgnia Y (2008) NGA ground motion model for the geometric mean horizontal component of PGA, PGV, PGD and 5\%-damped linear elastic response spectra for periods ranging from 0.01 to $10 \mathrm{~s}$. Earthq Spectra 24:139-171

Cauzzi C, Faccioli E (2008) Broadband (0.05 to $20 \mathrm{~s}$ ) prediction of displacement response spectra based on worldwide digital records. J Seismol 12:453-475

Chiou BS-J, Darragh R, Gregor N, Silva W (2008) NGA project strong-motion database. Earthq Spectra 24:2344

Chiou BS-J, Youngs RR (2008) An NGA model for the average horizontal component of peak ground motion and response spectra. Earthq Spectra 24:173215

Chiou BS-J, Youngs RR, Abrahamson NA, Addo K (2010) Ground-motion attenuation model for smallto-moderate shallow crustal earthquakes in California and its implications on regionalization of groundmotion prediction models. Earthq Spectra 26:907-926

Cooke RG (1991) Experts in uncertainty: opinion and subjective probability in science. Oxford University Press, USA

Cornell CA (1968) Engineering seismic risk analysis. Bull Seismol Soc Am 58:1583-1606

Cotton F, Pousse G, Bonilla F, Scherbaum F (2008) On the discrepancy of recent European ground-motion observations and predictions from empirical models: analysis of KiK-net accelerometric data and point-sources stochastic simulations. Bull Seismol Soc Am 98:22442261

Cotton F, Scherbaum F, Bommer JJ, Bungum H (2006) Criteria for selecting and adjusting ground-motion models for specific target regions: application to central Europe and rock sites. J Seism 10:137-156

Danciu L, Tselentis G-A (2008) Engineering groundmotion parameters attenuation relationships for Greece. Bull Seismol Soc Am 97:162-183

Delavaud E, Scherbaum F, Kühn N, Allen T (2012) Testing the global applicability of ground motion prediction equations for active shallow crustal regions. Bull Seismol Soc Am (in press). doi:10.1785/0120110113

Douglas J (2008) Further errata of and additions to "ground motion estimation equations 1964-2003". Final Report BRGM/RP-56187-FR, p 118

Douglas J (2011) Ground-motion prediction equations 1964-2010. Final Report BRGM/RP-59356-FR, p 446

Douglas J, Bungum H, Scherbaum F (2006) Groundmotion prediction equations for Southern Spain and Southern Norway obtained using the composite hybrid model perspective. J Earthquake Eng 10:33-72

Drouet S, Cotton F, Beauval C (2010) Deliverable 4.2: regionally adjusted ground motion prediction equations (GMPE) for Europe. Technical report, LGIT/CNRS/Universit Joseph Fourier, Grenoble, France. Report for the European project FP7ENVIRONMENT-226967 "Seismic Hazard Harmonisation in Europe", p 81

Drouet S, Scherbaum F, Cotton F, Souriau A (2007) Selection and ranking of ground motion models for seismic hazard analysis in the Pyrenees. J Seism 11:87-100

Faccioli E, Bianchini A, Villani M (2010) New ground motion prediction equations for $\mathrm{t}>1 \mathrm{~s}$ and their influence on seismic hazard assessment. In: Proceedings of the University of Tokyo Symposium on LongPeriod Ground Motion and Urban Disaster Mitigation, March 17-18, Tokyo, Japan

Faccioli E, Villani M (2009) Seismic hazard mapping for Italy in terms of broadband displacement response spectra. Earthquake Spectra 25:515-539

Garcia D, Singh SK, Herráiz M, Ordaz M, Pacheco JF (2005) Inslab earthquakes of central Mexico: peak ground-motion parameters and response spectra. Bull Seismol Soc Am 95:2272-2282

Goossens LHJ, Harper FT, Kraan BCP, Métivier H (2000) Expert judgment for a probabilistic accident consequence uncertainty analysis. Radiat Prot Dosim 90:295-301

Grünthal G, Arvidsson R, Bosse C (2010) Earthquake model for the European-Mediterranean region for the purpose of GEM1. GEM Scientific Technical Report STR10/04

Hiemer S, Wang Q, Jackson D, Kagan Y, Wiemer S, Zechar J Woessner J (2011) Stochastic earthquake source model: satisfying accepted laws. In: Abstract of STATSEI 7-7th international workshop on statistical seismology, Santorini, Greece

Idriss IM (2008) An NGA empirical model for estimating the horizontal spectral values generated by shallow crustal earthquakes. Earthquake Spectra 24: 217-242

Jiménez MJ, Giardini D, Grünthal G, SESAME-WorkingGroup (2001) Unified seismic hazard modelling throughout the Mediterranean region. Boll Geof Teor Appl 42:3-18

Kaklamanos J, Baise LG, Boore DM (2011) Estimating unknown input parameters when implementing the NGA ground-motion prediction equations in engineering practice. Earthquake Spectra 27:12191235 
Kalkan E, Gülkan P (2004) Empirical attenuation equations for vertical ground motion in Turkey. Earthquake Spectra 20:853-882

Kanno T, Narita A, Morikawa N, Fujirawa H, Fukushima Y (2006) A new attenuation relation for strong ground motion in Japan based on recorded data. Bull Seismol Soc Am 96:879-897

Lin P-S, Lee C-T (2008) Ground-motion attenuation relationships for subduction zone earthquakes in northeastern Taiwan. Bull Seismol Soc Am 98:220-240

Luzi L, Hailemikael S, Bindi D, Pacor F, Mele F, Sabetta F (2008) ITACA (Italian Accelerometric Archive): a web portal for the dissemination of Italian strongmotion data. Seism Res Lett 79:716-722

Massa M, Morasca P, Moratto L, Marzorati S, Costa G, Spallarossa D (2008) Empirical ground-motion prediction equations for northern Italy using weak- and strong-motion amplitudes, frequency content, and duration parameters. Bull Seismol Soc Am 98:13191342

McVerry GH, Zhao JX, Abrahamson NA, Somerville PG (2006) New Zealand acceleration response spectrum attenuation relations for crustal and subduction zone earthquakes. Bull NZ Soc Earthqu Eng 39:1-58

Montaldo V, Faccioli E, Zonno G, Akinci A, Malagnini L (2005) Treatment of ground-motion predictive relationships for the reference seismic hazard map of Italy. J Seism 9:295-316

Musson RMW (1999) Probabilistic seismic hazard maps for the north Balkan region. Annali Geofis 42:1109-1124

Özbey C, Sari A, Manuel L, Erdik M, Fahjan Y (2004) An empirical attenuation relationship for northwestern Turkey ground motion using a random effects approach. Soil Dyn Earthquake Eng 20:853-882

Pagani M, Monelli D, Crowley H, Danciu L, Field EH, Wiemer S, Giardini D (2010) GEM1 hazard: description of input models, calculation engine and main results. GEM Technical Report 2010-3. GEM Foundation, Pavia, Italy

Pankow, KL, Pechmann JC (2004) The SEA99 groundmotion predictive relations for extensional tectonic regimes: revisions and a new peak ground velocity relation. Bull Seismol Soc Am 94:341-348

Papaioannou C, Papazachos C (2000) Time-independent and time-dependent seismic hazard in Greece based on seismogenic sources. Bull Seismol Soc Am 90:2233
Sabetta F, Lucantoni A, Bungum H, Bommer JJ (2005) Sensitivity of PSHA results to ground motion prediction relations and logic-tree weights. Soil Dyn Earthquake Eng 55:317-329

Sandikkaya MA, Yilmaz MT, Bakir BS, Yilmaz Ö (2010) Site classification of Turkish national strong-motion stations. J Seism 14:543-563

Scasserra G, Stewart JP, Bazzurro P, Lanzo G, Mollaioli F (2009) A comparison of NGA ground-motion prediction equations to Italian data. Bull Seismol Soc Am 99:2961-2978

Scherbaum F, Bommer JJ, Bungum H, Cotton F, Abrahamson NA (2005) Composite ground-motion models and logic-trees: methodology. Bull Seismol Soc Am 95:1575-1593

Scherbaum F, Delavaud E, Riggelsen C (2009) Model selection in seismic hazard analysis: an informationtheoretic perspective. Bull Seismol Soc Am 99:32343247

Scherbaum F, Kühn N (2011) Logic tree branch weights and probabilities: summing up to one is not enough. Earthquake Spectra 27:1237-1251

Sokolov V, Bonjer K-P, Wenzel F, Grecu B, Radulian M (2008) Ground-motion prediction equations for the intermediate depth vrancea (Romania) earthquakes. Bull Earthquake Eng 6:367-388

Tavakoli B, Pezeshk S (2005) Empirical-stochastic groundmotion prediction for eastern North America. Bull Seismol Soc Am 95:2283-2296

Toro GR, Abrahamson NA, Schneider JF (1997) Model of strong ground motions from earthquakes in central and eastern North America: best estimates and uncertainties. Seism Res Lett 68:41-57

Van Houtte C, Drouet C, Cotton F (2011) Analysis of the origins of $\kappa$ (kappa) to compute hard rock to rock adjustment factors for GMPEs. Bull Seismol Soc Am 101:2926-2941

Youngs RR, Chiou BS-J, Silva WJ, Humphrey JR (1997) Strong ground motion attenuation relationships for subduction zone earthquakes. Seism Res Lett 68:5873

Zhao JX, Zhang J, Asano A, Ohno Y, Oouchi T, Takahashi T, Ogawa H, Irikura K, Thio HK, Somerville P, Fukushima Y, Fukushima Y (2006) Attenuation relations of strong ground motion in Japan using site classification based on predominant period. Bull Seismol Soc Am 96:898-913 